\title{
Retraction Note: Detection of PM2.5 in mountain air based on fuzzy multi-attribute and construction of folk sports activities
}

\author{
Guanming $\mathrm{Liu}^{1} \cdot \mathrm{Lin} \mathrm{Gan}^{2} \cdot$ Huailong Yang ${ }^{3} \cdot$ Changyue Wang ${ }^{4}$
}

Published online: 22 November 2021

C) Saudi Society for Geosciences 2021

Retraction Note: Arabian Journal of Geosciences (2021) 14: 1847

https://doi.org/10.1007/s12517-021-08210-z

The Editor-in-Chief and the Publisher have retracted this article because the content of this article is nonsensical. The peer review process was not carried out in accordance with the Publisher's peer review policy. Guanming Liu has not responded to correspondence regarding this retraction. The Publisher has not been able to obtain a current email address for authors Lin Gan, Huailong Yang and Changyue Wang.

The online version of the original article can be found at https:// doi.org/10.1007/s12517-021-08210-z

Guanming Liu gm159836@163.com

1 Physical Education Department, Northeastern University, Shenyang, China

2 School of Humanities and Law, Northeastern University, Shenyang, China

3 Department of Sports Training, Shenyang Sport University, Shenyang, China

4 Sports Department, Northeastern University, Shenyang, China 